\title{
mRNA Biogenesis in the Nucleus and Its Export to the Cytoplasm
}

\author{
Naoko Fujiwara, Takuya Shiki and Seiji Masuda \\ Division of Integrated Life Science, Graduate School of Biostudies, Kyoto University, \\ Japan
}

\section{Introduction}

Fail-safe biogenesis of mRNA is crucial for translating genetic information into proteins in a high-fidelity manner. This process occurs in the nucleus and involves various mRNA processing steps. Recent findings indicate that these mRNA processing steps and the export of mRNA into the cytoplasm are linked in eukaryotic cells. This link is called 'coupling' and is thought to be indispensable for precise and efficient gene expression, because this coupling mechanism is conserved among many species. Through this coupling mechanism, only the properly-processed mRNAs are efficiently exported to the cytoplasm where protein synthesis occurs. Various mRNA binding proteins are identified to function in this system. Most of these proteins are recruited to the transcripts at an early stage of the mRNA lifecycle. Moreover, these proteins remain associated with the transcripts to a much later stage and function by prompting mRNA processing in the nucleus, coupling the mRNA processing steps and its export and surveillance of the improperly-processed mRNA in the cytoplasm. Here we review mRNA biogenesis in eukaryotic cells with an emphasis on the importance of this coupling mechanism for highfidelity gene expression.

\section{2. mRNA transcription by RNA polymerase II}

The transcription of mRNA is the first step of translating genetic information into a protein. This genetic information encoded in the DNA is transcribed into mRNA by a huge molecular machine called RNA polymerase II (Pol II). Pol II is responsible for transcribing all the protein-coding genes.

\subsection{Initiation}

At the first stage of the transcription process, Pol II needs to be recruited to a gene promoter. Pol II cannot recognize the promoters of target genes alone. Instead, Pol II depends on a series of accessory factors known as general transcription factors (GTFs) (Orphanides et al., 1996; Roeder, 1996; Woychik and Hampsey, 2002). Pol II and the associated GTFs termed TFIIA, TFIIB, TFIID, TFIIE, TFIIF and TFIIH assemble on the promoter to form the preinitiation complex (PIC). Mediator, a large multisubunit complex, regulates PIC 
assembly, integrating various regulatory signals into the transcriptional activity (Conaway and Conaway, 2011). After the formation of PIC on the promoter, TFIIH, a complex harboring DNA helicases, melts the DNA to expose the template strand. Then RNA synthesis begins.

Once the first nucleotide bonds have been formed, Pol II is released from the promoter to facilitate downstream transcription. Most of the general transcription factors dissociate from the promoter, whereas mediator is likely to remain associated at the promoter to facilitate the next round of polymerase recruitment and reinitiation (Yudkovsky et al., 2000).

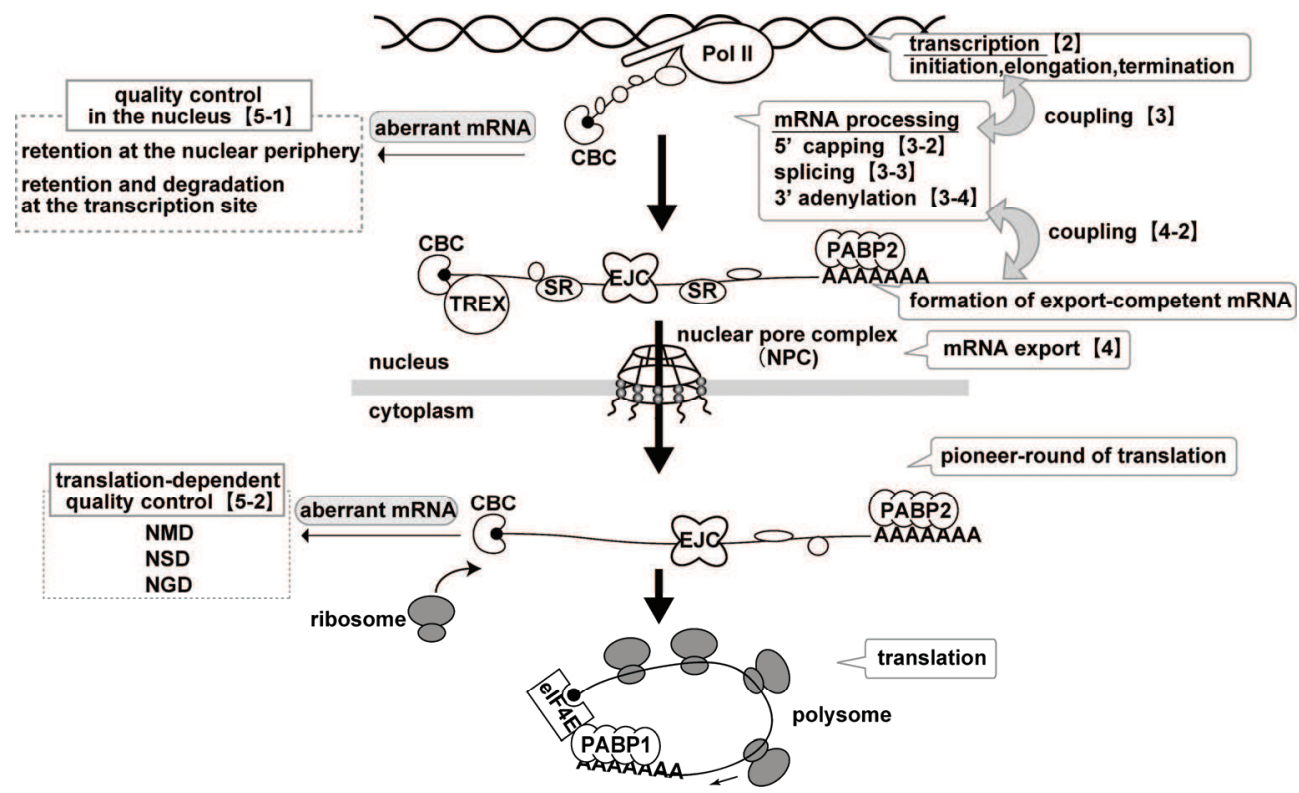

Fig. 1. mRNA lifecycle

RNA polymerase II complex (Pol II) transcribes all the protein-coding genes in the nucleus. Transcribed pre-mRNA undergoes the various processing steps. Immature mRNA is held in the nucleus and degraded. Only the properly-processed mRNA is exported from the nucleus to the cytoplasm. In the cytoplasm, there are other quality check systems that are associated with the pioneer-round of translation and degrade the aberrant mRNA. Hence, only the properly-processed mRNA managing to pass all of these exams can serve as the template for protein synthesis.

\subsection{Promoter-proximal pausing}

The recruitment of Pol II to the promoter is believed to be the rate-limiting step in gene expression (Saunders et al., 2006). However, recent genome-wide studies using drosophila and mammalian cells suggest that a number of developmental and inducible genes contain stalled Pol II in their promoter-proximal regions, that is 20-50 nt downstream from the transcription start site (Aida et al., 2006; Barboric and Peterlin, 2005; Bender et al., 1987; 
Gilmour and Lis, 1986; Krumm et al., 1992; Saunders et al., 2006; Sims et al., 2004; Strobl and Eick, 1992). Moreover, activation of the stalled Pol II is thought to be responsible for the expression of these genes (Saunders et al., 2006). DRB sensitivity-inducing factor (DSIF) and the negative elongation factor (NELF) (Wu et al., 2003; Yamaguchi et al., 2002) are found to be associated with the pausing Pol II. TFIIS, TFIIF and the positive transcription-elongation factor-b (P-TEFb) assist in rescuing Pol II from this pause state (Adelman et al., 2005; Peterlin and Price, 2006). Pol II stalling is enriched at highly regulated genes that are essential for responses to stimuli or embryonic development (Muse et al., 2007; Zeitlinger et al., 2007). Pol II stalling at the promoter supports the quick expression of these genes (Lorincz and Schubeler, 2007; Saunders et al., 2006).

\subsection{Elongation}

A number of factors interact with Pol II during the transition into productive elongation, such as P-TEFb mentioned above. Once Pol II engages in productive elongation, the mature Pol II complex is remarkably stable and can transcribe hundreds of kilobases without dissociating from the DNA template (Singh and Padgett, 2009).

\subsection{Termination}

Transcriptional termination is crucial for the release of the transcripts from the transcription site. This process also facilitates Pol II release from the DNA template, promoting Pol II recycling for further rounds of transcription. Pol II release also contributes to proper gene regulation. Without such events, the correct function of neighboring genes may be influenced because of the "penetrating" Pol II from an upstream gene.

Currently, two models describing transcriptional termination of protein-coding genes are proposed. Pol II termination is known to be functionally coupled to an RNA maturation step called 3' adenylation (see below). During the 3' adenylation, the stalling of Pol II, the endonucleolytic cleavage of the nascent transcripts and the subsequent degradation of the downstream transcript occur. One of the models is called the 'allosteric model' which proposes that Pol II stalling during 3' adenylation causes a conformational change in Pol II, which makes Pol II lose its processivity and leads to dissociation of Pol II from the template (Calvo and Manley, 2001; Greenblatt et al., 1993; Logan et al., 1987). The second model is the 'torpedo model'. The model proposes that a $5^{\prime}$ to $3^{\prime}$ RNA exonuclease involved in the clearance of downstream byproducts of the $3^{\prime}$ adenylation catches up to the elongating Pol II and causes it to terminate (Connelly and Manley, 1988).

\section{Coupling transcription to mRNA processing steps}

Once RNA synthesis starts, the transcribed pre-mRNA undergoes three major processing steps and these processing steps occur co-transcriptionally (Buratowski, 2009; Egloff and Murphy, 2008; Fuda et al., 2009; Koch et al., 2008; Kuehner et al., 2011). They are 5' capping, splicing and $3^{\prime}$ adenylation. The proper completion of these processing steps is necessary for the production of export-competent mature mRNA molecules. Although the biochemical basis of each step is distinct, they are all coupled to transcription. A unique carboxyterminal domain (CTD) on Rpb1, the largest subunit of Pol II, provides the platform for this 
coupling system (Proudfoot et al., 2002). The data that $5^{\prime}$ capping, splicing and $3^{\prime}$ adenylation are all inhibited by the truncation of CTD without affecting transcription provides evidence for the important role of CTD in coupling transcription to these processing steps (McCracken et al., 1997).

\subsection{Phosphorylation status of CTD during mRNA synthesis}

CTD is a conserved repeat of the heptapeptide Tyr-Ser-Pro-Thr-Ser-Pro-Ser (Cramer et al., 2001). The number of repeats is 26 in yeast and 52 in humans. A unique feature of CTD is that its pattern of phosphorylation changes dynamically according to the transcriptional activity of Pol II (Buratowski, 2009; Egloff and Murphy, 2008; Fuda et al., 2009; Koch et al., 2008; Kuehner et al., 2011).

During the PIC assembly, Pol II with unphosphorylated CTD is recruited to the gene promoters. The mediator binds unphosphorylated Pol II. Then, within the PIC, TFIIH phosphorylates the CTD on Ser5, which leads to the release of mediator from Pol II. This allows Pol II to engage in processive transcription and depart from the promoter (Max et al., 2007). Even if Pol II harbors Ser5P CTD, it may still stall at the promoter-proximal region and synthesize short and abortive transcripts as described above. As Pol II manages to escape from pausing and transcribes further downstream, the level of Ser5P decreases; however, a low level of Ser5P is maintained throughout the elongation process. Subsequently, Ser2 is phosphorylated by Cdk9, a kinase subunit of the positive elongation factor P-TEFb as well as the elongation factor DSIF (also known as Spt4/Spt5), that leads to transcription into a gene body (Peterlin and Price, 2006). Along with transcriptional termination, Ser2P is dephosphorylated and this may help Pol II reinitiate transcription.

Each of these different modification patterns preferentially recruits a distinct set of processing factors at the right time during mRNA transcription and maturation. Furthermore, according to the X-ray study of yeast Pol II, CTD resides adjacent to the narrow tunnel for nascent transcripts to exit. This location appears to be appropriate for CTD-associating factors to work on pre-mRNAs (Fabrega et al., 2003) .

\subsection{Coupling to 5' capping}

Capping is the first modification to the pre-mRNA. This is an m7GpppN structure added at the $5^{\prime}$ end of the nascent transcript. In the nucleus, this structure is recognized by the cap binding complex (CBC) (Izaurralde et al., 1994), which contains CBP20 and CBP80. The $\mathrm{CBC}$-bound cap structure functions to protect the nascent transcript from attack by nucleases. It also has important roles both in the export of mature mRNAs from the nucleus and the quality control of mRNAs (Proudfoot et al., 2002). In the cytoplasm, the cap structure also serves as the binding site for the eukaryotic elongation factor eIF4E to recruit the ribosome.

Capping occurs after 20-30 nt of RNA is synthesized from the transcription start site and involves two enzymes, HCE (Human Capping Enzyme) and MT (RNA 7-methyltransferase) (Hirose and Manley, 2000). These capping enzymes bind specifically to the Ser5P CTD of Pol II (Fabrega et al., 2003). Ser5P CTD is most abundant in the promoter-proximal region and ensures the 5 'capping of the pre-mRNA at the earliest stage of the transcription process. 


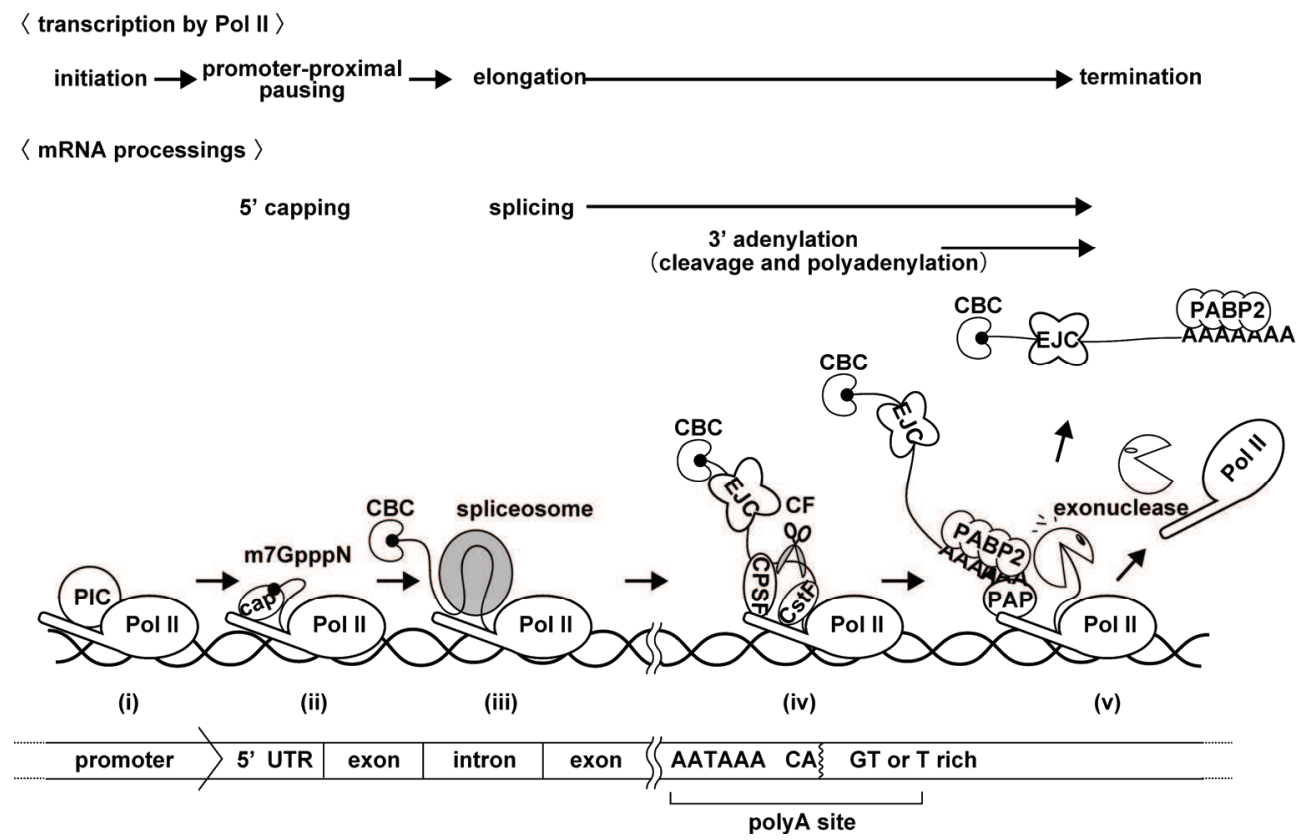

Fig. 2. Coupling transcription to mRNA processing steps

Here we present the overview of the coupling between Pol II transcription and mRNA processing steps. Transcription begins with the assembly of the transcriptional initiation complex (PIC) on the promoter (i). Soon after RNA synthesis begins, m7pppGN cap structure is added to the $5^{\prime}$ end of transcript (ii). Processive elongation stimulates the recruitment of spliceosome (iii). At the polyA site, pre-mRNA is cleaved and subsequently adenylated. $3^{\prime}$ adenylation provokes the transcriptional termination to make Pol II dissociate from DNA template (iv, v).

\subsection{Coupling to splicing}

Most mammalian genes contain introns. Since these sequences represent 'non-coding' parts of the gene, in order to make a functional protein, introns must be removed from the template by means of splicing. Along with the completion of splicing, the exon-exon junction complex (EJC) is deposited about $24 \mathrm{nt}$ upstream of the exon-exon junctions (Le Hir and Andersen, 2008; Tange et al., 2004). EJC plays important roles in mRNA export from the nucleus and in cytoplasmic mRNA quality control (see below).

The pre-mRNA contains several cis-elements that are essential for the splicing reaction, such as $5^{\prime}$ splice site, the branch-point, the poly-pyrimidine tract and the $3^{\prime}$ splice site. These elements are recognized by the spliceosome, a large protein-RNA complex. The two sequential trans-esterification reactions carried out by the spliceosome lead to the ligation of the exon sequences and the excision of the introns. To accomplish the precise splicing, the proper recognition of these cis-elements by the spliceosome is crucial. To aid spliceosome deposition, there are other auxiliary sequences within the pre-mRNA. For example, a 
sequence within an exon is called the 'exonic splicing enhancer' (ESE) (Chew et al., 1999; Wang et al., 2005; Wu et al., 2005). The serine/arginine-rich (SR) family of essential splicing factors play a particularly important role in splicing by binding to the ESE and recruiting the rest of the splicing machinery(Cartegni and Krainer, 2002; Cramer et al., 1999; Liu et al., 1998; Sun et al., 1993).

Transcripts derived from Pol II transcription are more efficiently spliced than those transcribed by T7 which lacks CTD (Das et al., 2006). Introducing mutations within the CTD greatly reduces the efficiency of splicing without affecting transcription as well as inhibition of CTD phosphorylation by kinase inhibitors (Bentley, 2005; Bird et al., 2004). Therefore, phosphorylated CTD seems to be crucial for the coupling of transcription and splicing. Several splicing factors such as U1 snRNP, a component of the spliceosome, and the SR protein factors directly associate with Pol II through the CTD (Das et al., 2007). Some SR proteins bind indirectly to the CTD of Pol II (Das et al., 2007; de Almeida and CarmoFonseca, 2008). These physical interactions seem to play a role in coordinating the transcriptional activity with the efficiency of splicing.

\subsection{Coupling to 3' adenylation and transcription termination}

Most of the protein-coding mRNAs undergo 3' adenylation. At the $3^{\prime}$ end of the transcript, a polyadenosine tail (polyA tail) of approximately 200-300 nt is added (Danckwardt et al., 2008; Proudfoot et al., 2002). Pre-mRNA is cleaved prior to polyadenylation. The cleavage occurs at a CA dinucleotide defined by the sequence elements within the 3 ' end region of the pre-mRNA. These elements consist of the AAUAAA consensus sequence and the U/GU-rich region (downstream sequence element or DSE) that is located 10-30 nt upstream and $30 \mathrm{nt}$ downstream of the cleavage site, respectively. Multiple protein factors assemble onto these sequence elements to define the cleavage site. Cleavage and the polyadenylation specificity factor (CPSF) binds to the AAUAAA sequence, resulting in the pausing of Pol II transcription (Glover-Cutter et al., 2008). After the cleavage stimulation factor (CstF) binds to the U/GU-rich region, CPSF binds to CstF (Kazerouninia et al., ; Kuehner et al., 2011; Nag et al., 2007; Park et al., 2004). Since the binding of CPSF to CstF is mutually exclusive with Pol II binding (Nag et al., 2007), that binding event induces the release of paused Pol II and the CPSF-mediated cleavage. The upstream cleavage product is polyadenylated, whereas the downstream cleavage product is degraded. CPSF is associated with the elongation complex by interaction with the Pol II body and CstF interacts with CTD. In yeast, Pcf11, a subunit of the cleavage/polyadenylation factor, binds preferentially to the Ser 2P CTD via its CID (CTD-interacting domain) (Licatalosi et al., 2002). Moreover, purified Pol II or CTD can stimulate $3^{\prime}$ adenylation in vitro (Hirose and Manley, 1998). Thus, the efficiency of the $3^{\prime}$ adenylation is dramatically enhanced by coupling to transcription.

As mentioned above, transcriptional termination is tightly linked to $3^{\prime}$ adenylation (Logan et al., 1987; Whitelaw and Proudfoot, 1986). A functional polyA site (Zaret and Sherman, 1982) and several essential subunits of the cleavage factor including Pcf11 are necessary for Pol II termination(Birse et al., 1998; Gross and Moore, 2001; Minvielle-Sebastia et al., 1997). These data explain why CTD is required for optimal termination of transcription downstream of the polyA site (McCracken et al., 1997; McNeil et al., 1998). Thus, the elongation machinery stimulates both $3^{\prime}$ adenylation and transcriptional termination. 


\section{4. mRNA export}

In eukaryotes, the nucleus is physically segregated from the cytoplasm by the nuclear envelope. Transcription and subsequent processing occur in the nucleus, whereas translation is a cytoplasmic event, therefore, processed mRNAs must be transported from the nucleus to the cytoplasm for translation.

Nucleocytoplasmic transport events occur through the nuclear pore complex (NPC) that penetrates the nuclear envelope (Kohler and Hurt, 2007; Mattaj and Englmeier, 1998). The NPC is imaged like a spouted basket, and allows the bidirectional transport of macromolecules such as proteins or RNA molecules between the nucleus and the cytoplasm. The transported cargoes, that are imported into or exported from the nucleus, are recognized by different transport receptors.

\subsection{Tap-p15 mRNA export factor and its adaptors}

The export receptor of mRNA is the Tap and p15 (Mex67 and Mtr2 in yeast) heterodimer complex (Gruter et al., 1998; Segref et al., 1997). The stable interaction with NPC is not accomplished only by Tap, but also requires heterodimerization with p15 (Guzik et al., 2001). In the absence of the Tap-p15 association, the mRNA is retained in the nucleus by the mRNA quality control system (Fasken and Corbett, 2009; Moraes, 2010).

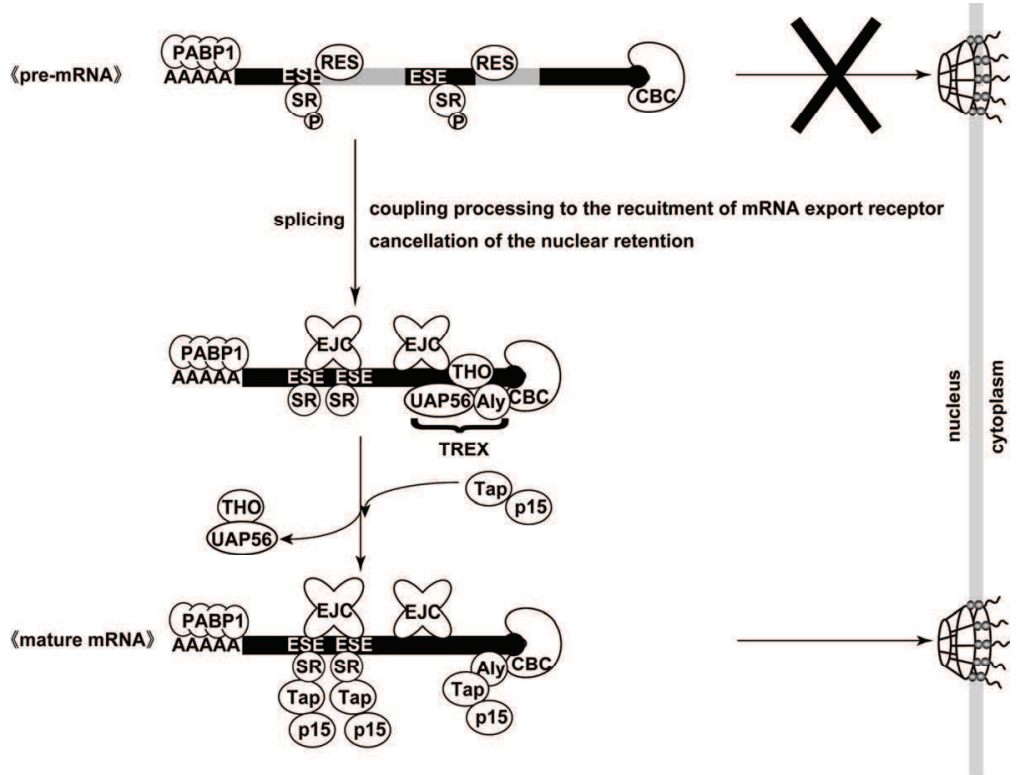

Fig. 3. Coupling splicing to export.

Because mRNA processing is coupled to its export, the proper processing facilitates mRNA export into the cytoplasm. Black bars represent exons and gray bars represent introns. As splicing proceeds, the TREX complex is loaded onto mRNA and SR proteins on ESEs become hypophsophrylated. These factors function as adaptors for Tap/p15, mRNA export receptor. On the other hand, unspliced pre-mRNA is retained in the nucleus by the nulear retention activity of RES. Please see text for other nuclear retention mechanisms. 
Numerous additional factors cooperate with the mRNA export receptor. The role of these factors is to establish a physical bridge between the mRNA and its export receptor Tap-p15. One of the important adaptors is the TREX (transcription-export) complex that consists of the Ref family protein Aly (Yra1 in yeast), UAP56 (Sub2 in yeast) and the THO complex (Masuda et al., 2005; Strasser et al., 2002). Because the direct interaction of mRNA and Mex67 appears to be weak, the TREX subunit Aly/Yra1 mediates interaction between mRNA and the Tap/Mex67 complex (Reed, 2003; Reed and Hurt, 2002).

Another class of mRNA export adaptors is the SR proteins. As mentioned above, the SR proteins have essential roles in splicing. Some of the SR proteins such as SF2/ASF and 9G8 function as mRNA export adaptors as well (Huang et al., 2003).

\subsection{Coupling transcription and processing to nuclear export}

Remarkably, these adaptors are attached to transcripts as pre-mRNA processing steps proceed.

The TREX complex is recruited onto mRNA during splicing (Masuda et al., 2005) and associates with the cap binding complex (CBC) through a direct interaction between Aly and CBC (Cheng et al., 2006; Nojima et al., 2007). Later the TREX complex is thought to be replaced by the Tap-p15 mRNA export receptor. Hence, the TREX complex integrates transcription or splicing with nuclear export. A study using electron microscopy revealed that the fully maturated mRNA is exported in the $5^{\prime}$ to $3^{\prime}$ direction (Visa et al., 1996); therefore, the association of the TREX complex at the cap site seems to guide the directional mRNA export.

SR proteins are recruited to the splicing machinery in a hyperphosphorylated form and become hypophosphorylated after splicing. The change in the phosphorylation state triggers the recruitment of TAP-p15 (Huang et al., 2003). The phosphorylation status of the SR proteins could act as a switch to signal the export competence of the spliced mRNP.

The importance of the coupling of mRNA export to transcription was initially suggested by the observation that spliced mRNAs exit the nucleus more efficiently than unspliced mRNAs or RNAs derived from cDNAs (Luo and Reed, 1999). Splicing-dependent recruitment and stabilization of these adaptors explains why mRNAs produced from intron containing genes are more efficiently exported than mRNAs derived from cDNAs.

Besides these factors described above, a complex called TREX-2 is proposed to functionally couple transcription and mRNA export. TREX-2 is composed of Sac3, Thp1, Sus1 and Cdc31 (Fischer et al., 2004; Rodriguez-Navarro et al., 2004). Sac3 was originally identified as an additional mRNA export adaptor in yeast (Fischer et al., 2002). Sac3 physically associates with the Mex67-Mtr2 export receptor. Sus1 in the TREX-2 complex interacts with SAGA, a large transcription initiation complex that catalyzes histone acetylation and deubiquitylation (Kohler et al., 2006; Shukla et al., 2006). TREX-2 and SAGA generate a physical contact with the NPC. TREX-2 therefore couples SAGA-dependent gene transcription to mRNA export both by facilitating the export receptor loading onto transcribed mRNAs and by bringing the transcription site closer to NPC. 


\subsection{The role of Dbp5-Gle1 and IP6 in the release of mRNA into the cytoplasm}

To ensure the unidirectional transport of cargo, transport receptors need cues to determine which side of the NPC they are on. A shuttling of proteins between the nucleus and the cytosol requires a family of conserved nuclear transport receptors known as karyopherins (Chook and Blobel, 2001; Mosammaparast and Pemberton, 2004; Strom and Weis, 2001). Importin $\beta$ family proteins, the most studied karyopherins, directly or indirectly recognize cargo signals. The affinity for cargoes and the direction of nucleocytoplasmic transport by the importin $\beta$ family of proteins is determined by the asymmetric nucleus/cytoplasm distribution of RanGTP and RanGDP; the so-called 'Ran gradient' (Gorlich and Kutay, 1999; Pemberton et al., 1998). In the case of nuclear export, the interaction between karyopherin and the cargo is stabilized by the RanGTP concentrated in the nucleus, whereas in the cytoplasm, RanGDP, which is derived from RanGTP hydrolysis by RanGAP, causes the complex to disassemble and terminate the export step.

In contrast, bulk mRNA export does not depend on karyopherins or the Ran gradient. If the Tap-p15 heterodimer still interacts with mRNA at the NPC, mRNA could be returned to the nucleus. Dbp5-Gle1 and inositol hexakisphosphate (IP6) function to ensure the unidirectional export of mRNA into the cytoplasm.

In yeast, Dbp5 removes Mex67 from mRNA in vivo and displaces the RNA binding protein Nab2 in vitro (Lund and Guthrie, 2005; Tran et al., 2007). Consequently, Dbp5 remodels the profile of proteins binding to transcripts, thus preventing mRNA from returning to the nucleus. Dbp5 is a DEAD-box RNA helicases. DEAD-box RNA helicases are highly conserved among eukaryotes and contain a highly conserved core with ATP-binding and RNA-binding sites (Rocak and Linder, 2004). DEAD-box RNA helicases conjugate their ATPase activities to their helicase activities. The ATP-bound form of Dbp5, "closed form", sandwiches RNA, but the ADP-bound form, "open form", releases RNA (Ledoux and Guthrie, 2011). Moreover, only the ADP-bound Dbp5 can remove Nab2 from mRNA, whereas ATP-bound Dbp5 does not. Consequently, the alteration of ATP to ADP within Dbp5 may be crucial for its remodeling activity. Dbp5 exhibits quite low ATPase activity on its own. Gle1 and IP6 activate the ATPase activity of Dbp5 (Dossani et al., 2009; Weirich et al., 2006). Recently, the Dbp5-Gle1 and IP6 complex was shown to be structurally similar to the eIF4A-eIF4G complex which is essential for translation initiation. eIF4A is a DEAD-box family protein, and eIF4G activates eIF4A exactly as Gle activates Dbp5 (Montpetit et al., 2011). Dbp5 is concentrated at the cytoplasmic face of the NPC where it interacts with the nucleoporin Nup159 (NUP214/CAN in human) (Weirich et al., 2004). On the other hand, Dbp5 is relatively abundant and also localizes in the cytoplasm. Remarkably, Dbp5 shuttles between the nucleus and the cytoplasm, and the inhibition of Xpo1, an importin $\beta$ family protein, results in the accumulation of Dbp5 in the nucleus (Hodge et al., 1999). Moreover, it is reported that Dbp5 is recruited to mRNA at an early stage in the transcription process (Estruch and Cole, 2003). This raises the question of why Dbp5 removes Tap from mRNA only after transit through the NPC and not in the nucleus. The current model is shown in Fig.4. Gle1 is concentrated at the cytoplasmic face of the NPC via interaction with two cytoplasmic components of NPC, Nup42 (CG1 in human) and Nup159. As a result of this biased localization of Gle1, the ATPase of Dbp5 is activated only on the cytoplasmic side of the NPC. Then, Dbp5 should dissociate Mex67 from mRNA, and mRNA is unidirectionally exported to the cytoplasm. 


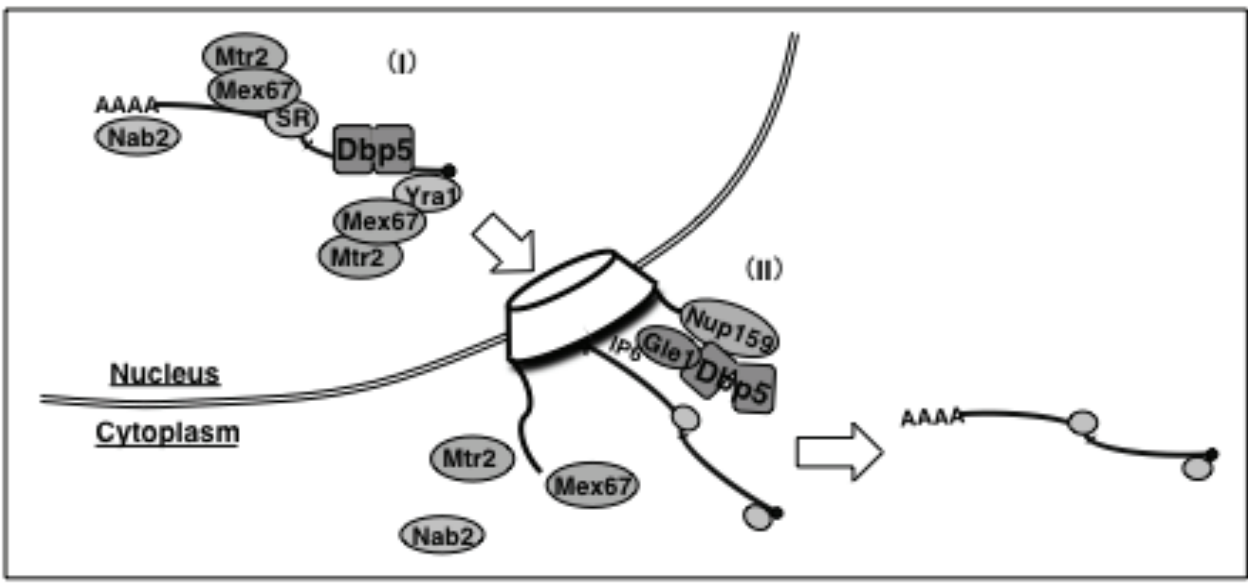

Fig. 4. The current model of mRNA export.

(I) Mex67-Mtr2 (Tap-p15 in human), mediated by Yra1 or SR proteins, exports mRNA to the NPC. (II) On the cytoplasmic side of the NPC, Dbp5, activated by Gle1 and IP6, removes RNA binding proteins including Mex67 from the mRNA, which is called 'remodeling'. Thereby, mRNA export to the cytoplasm is one-way traffic.

\subsection{Non-canonical mRNA export pathway}

The importin $\beta$ family protein $X$ po1, also known as Crm1, does not have a major role in mRNA export. However, Xpo1 is shown to be involved in nuclear export of a subset of transcripts, such as mRNAs containing adenosine/uridine-rich elements (AREs) positioned in their 3' untranslated regions (Barreau et al., 2005; Chen and Shyu, 1995).

\section{5. mRNA quality control}

When mRNA undergoes proper processing, it travels through the NPC to the cytoplasm for protein synthesis. However, if the mRNA is not properly processed, it should be held in the nucleus or be degraded to avoid the production of aberrant proteins that may disrupt cellular function. Currently, several mRNA quality control systems are found in the nucleus and the cytoplasm.

\subsection{Nuclear retention of aberrant mRNA}

Myosin-like proteins (Mlp1p and Mlp2p in yeast and Tpr in vertebrates) are filamentous proteins anchored at the NPC (Kohler and Hurt, 2007). Deletion of Mlp1 results in the leakage of unspliced transcripts into the cytoplasm (Galy et al., 2004). Mlp1 interacts with Nab2 (Fasken et al., 2008; Grant et al., 2008; Green et al., 2003; Vinciguerra et al., 2005), and the splice site-binding protein SF1 and the branch point-binding protein also interact with Mlp1 in an RNA-dependent manner (Galy et al., 2004). At the NPC, through sequestering unspliced transcripts or facilitating the export of mature mRNA, Mlps function as 'gatekeepers' to assure that only mature mRNAs are exported from the nucleus. In addition, pre-mRNA retention and 
the splicing (RES) complex, which binds to the SF3b subcomplex in the spliceosome, are also implicated in pre-mRNA retention in the nucleus (Kaida et al., 2007). Some ESEs have been shown to possess activity to retain unspliced mRNAs, and the splicing reaction can reset the nuclear retention state caused by the ESEs (Taniguchi et al., 2007).

Several data suggest that the improperly-processed transcripts are submitted to the retention at the transcription site and subsequently undergo degradation. The nuclear exosome nuclease complex plays a crucial role in this mRNA quality control in the nucleus. (Abruzzi et al., 2006; Bousquet-Antonelli et al., 2000; Burkard and Butler, 2000; Custodio et al., 1999; Das et al., 2003; Dower et al., 2004; Dunn et al., 2005; Hilleren et al., 2001; Libri et al., 2002; Milligan et al., 2005; Torchet et al., 2002; Zenklusen et al., 2002).

The exosome is a ring-shaped multimolecular complex involved in degradation of various RNAs both in the nucleus and the cytoplasm (see below for the function of exosome in cytoplasmic mRNA quality control) (Belostotsky, 2009; Houseley et al., 2006; Lebreton and Seraphin, 2008; Lorentzen et al., 2008; Lorentzen and Conti, 2006; Lykke-Andersen et al., 2009; Schmid and Jensen, 2008; van Hoof and Parker, 1999; Vanacova and Stefl, 2007). In the nucleus, the exosome interacts with its nuclear-specific binding partner, Rrp6. When mRNA processing, such as splicing or $3^{\prime}$ adenylation, is perturbed, transcripts are retained within foci near or at the transcription site and are degraded in an Rrp6dependent manner.

\section{2 mRNA quality control in the cytoplasm}

The mature mRNAs exported from the nucleus to the cytoplasm are now applied to translation. At the first translation round, so called the pioneer-round of translation, mRNA undergoes a quality check. At least three mechanisms are currently known (Houseley and Tollervey, 2008; Isken and Maquat, 2007; Shyu et al., 2008). They are nonsense-mediated mRNA decay (NMD) (Culbertson and Neeno-Eckwall, 2005; Isken and Maquat, 2008), nonstop decay (NSD) (Vasudevan et al., 2002) and no-go decay (NGD).

Some mutations can cause the emergence of a pre-mature termination codon (PTC) within the mRNA. Such nonsense mutations result in the production of C-terminally truncated proteins that may be harmful to the cell. After the splicing, EJC is deposited 20-24 nt upstream of the exon-exon junctions (Le Hir and Andersen, 2008; Tange et al., 2004).

Normal termination codons in mammalian transcripts are usually found within the last exon. Consequently, EJC should be displaced at a pioneer round of translation. However, if PTC is present more than 50-55 nt upstream of EJC, EJC remains on the transcripts and the translating ribosome meets EJC. This event triggers NMD to degrade PTC containing mRNA. Most PTC-containing mRNAs in mammals come from aberrant alternative splicing (McGlincy and Smith, 2008). Upf 1-3 proteins have a central role in facilitating the recognition of PTC (Muhlemann and Lykke-Andersen, 2010). PTC-containing mRNAs are degraded through two pathways. One is initiated through decapping at the $5^{\prime}$ end and/or deadenylation at the $3^{\prime}$ end. These reactions make it easy to degrade mRNA by exoribonucleases. In a second pathway, mRNA is first endonucleolytically cleaved by Smg6, and then degraded both in $5^{\prime}$ to $3^{\prime}$ and $3^{\prime}$ to $5^{\prime}$ direction by exonucleases (Muhlemann and Lykke-Andersen, 2010; Nicholson et al., 2010). 
During the pioneer-round of translation

(a) NMD( transcripts harboring PTC)

translational machinery recognizes remaining EJC

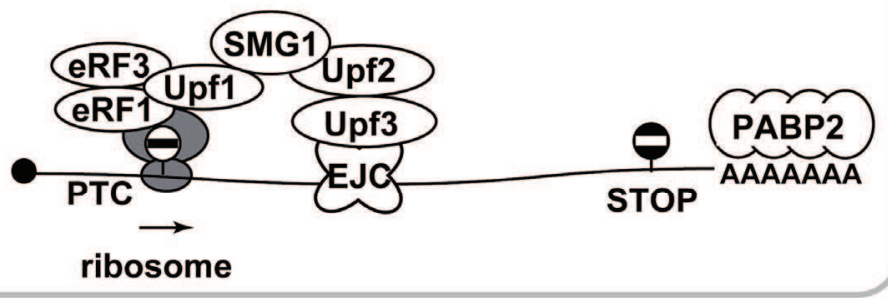

(b) NSD( transcripts without stop-codon)

Ski7-exosome complex recognizes stalled ribosomes

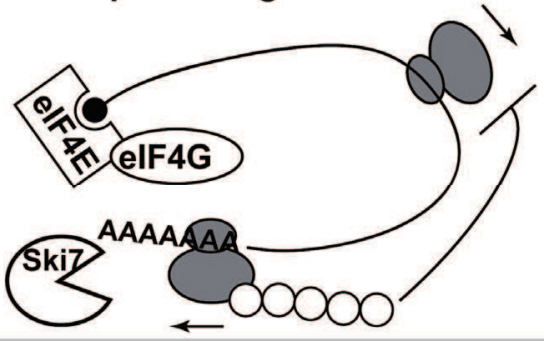

(c) NGD( transcripts with stable stem-loops or pseudo-knots )

Dom34-Hbs1 complex binds to stalled ribosomes

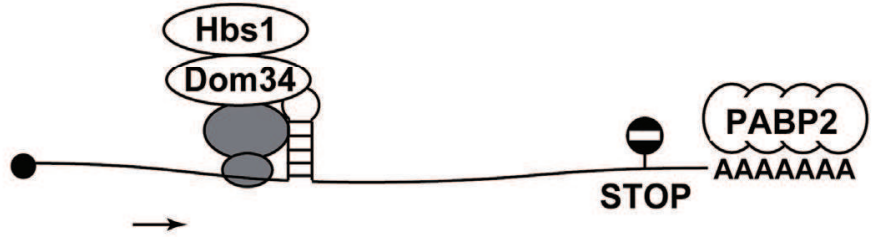

Fig. 5. mRNA quality control in the cytoplasm

When mRNA reaches the cytoplasm, it is applied to the first translation cycle; the so-called 'pioneer-round of translation'. During this translation, mRNA is submitted to the final quality check before the vigorous protein synthesis. Nonsense-mediated mRNA decay (NMD) for mRNAs harboring pre-mature termination codons (PTC) (a), non-stop decay (NSD) for mRNAs without functional termination codons (b) and no-go decay (NGD) for mRNAs with strong secondary structures are identified to participate in this translationcoupled quality control. 
mRNAs that lack the termination codons are also targeted for the translation-dependent mRNA decay, NSD. When a ribosome translates through the polyA tail because of the lack of a termination codon and stalls at the 3 '-end of the mRNA, Ski7, a component of the cytoplasmic exosome, interacts with the stalled ribosome and triggers the rapid degradation of the non-stop mRNA (Isken and Maquat, 2007).

Some mRNAs produced from aberrant alternative splicing contain strong secondary structures. Such structures prevent translation by the ribosome and cause the ribosome to stall. The ribosome is rescued by the NGD pathway. NGD clears the stalled ribosome and rapidly degrades the mRNA transcript (Doma and Parker, 2006). Dom34 and Hbs1 interact with the stalled ribosome and assist in the disassembly of the translational complex. They also trigger mRNA decay through endonucleolytic cleavage and subsequent exonucleolytic decay (Doma and Parker, 2007).

\section{Concluding remarks}

Various mRNA-processing proteins are recruited onto the transcripts at the early stage of the mRNA lifecycle. Besides their functions to facilitate pre-mRNA processing, they also serve as a 'dress-code' that indicates that the coded mRNA is properly processed and competent for export and translation. Pol II coordinates transcriptional activity for the recruitment of these factors to the transcripts. Hence, from its birth in the nucleus to its degradation in the cytoplasm, mRNA is kept under strict surveillance to ensure high-fidelity gene expression.

\section{Acknowledgment}

This work was supported by Sasakawa Scientific Research Grant from The Japan Society to N. F. and by grants-in-aid from the Ministry of Education, Culture, Sports, Science and Technology of Japan, Nagase Science and Technology Foundation, Central Miso Research Institute, The Kieikai Research Foundation and Hokto Bioscience Foundation to S. M.

\section{References}

Abruzzi, K. C., Belostotsky, D. A., Chekanova, J. A., Dower, K., and Rosbash, M. (2006). 3'end formation signals modulate the association of genes with the nuclear periphery as well as mRNP dot formation. Embo J 25, 4253-4262.

Adelman, K., Marr, M. T., Werner, J., Saunders, A., Ni, Z., Andrulis, E. D., and Lis, J. T. (2005). Efficient release from promoter-proximal stall sites requires transcript cleavage factor TFIIS. Mol Cell 17, 103-112.

Aida, M., Chen, Y., Nakajima, K., Yamaguchi, Y., Wada, T., and Handa, H. (2006). Transcriptional pausing caused by NELF plays a dual role in regulating immediateearly expression of the junB gene. Mol Cell Biol 26, 6094-6104.

Barboric, M., and Peterlin, B. M. (2005). A new paradigm in eukaryotic biology: HIV Tat and the control of transcriptional elongation. PLoS Biol 3, e76.

Barreau, C., Paillard, L., and Osborne, H. B. (2005). AU-rich elements and associated factors: are there unifying principles? Nucleic Acids Res 33, 7138-7150. 
Belostotsky, D. (2009). Exosome complex and pervasive transcription in eukaryotic genomes. Curr Opin Cell Biol 21, 352-358.

Bender, T. P., Thompson, C. B., and Kuehl, W. M. (1987). Differential expression of c-myb mRNA in murine B lymphomas by a block to transcription elongation. Science 237, 1473-1476.

Bentley, D. L. (2005). Rules of engagement: co-transcriptional recruitment of pre-mRNA processing factors. Curr Opin Cell Biol 17, 251-256.

Bird, G., Zorio, D. A., and Bentley, D. L. (2004). RNA polymerase II carboxy-terminal domain phosphorylation is required for cotranscriptional pre-mRNA splicing and 3'-end formation. Mol Cell Biol 24, 8963-8969.

Birse, C. E., Minvielle-Sebastia, L., Lee, B. A., Keller, W., and Proudfoot, N. J. (1998). Coupling termination of transcription to messenger RNA maturation in yeast. Science 280, 298-301.

Bousquet-Antonelli, C., Presutti, C., and Tollervey, D. (2000). Identification of a regulated pathway for nuclear pre-mRNA turnover. Cell 102, 765-775.

Buratowski, S. (2009). Progression through the RNA polymerase II CTD cycle. Mol Cell 36, 541-546.

Burkard, K. T., and Butler, J. S. (2000). A nuclear 3'-5' exonuclease involved in mRNA degradation interacts with Poly(A) polymerase and the hnRNA protein Npl3p. Mol Cell Biol 20, 604-616.

Calvo, O., and Manley, J. L. (2001). Evolutionarily conserved interaction between CstF-64 and PC4 links transcription, polyadenylation, and termination. Mol Cell 7, 10131023.

Cartegni, L., and Krainer, A. R. (2002). Disruption of an SF2/ ASF-dependent exonic splicing enhancer in SMN2 causes spinal muscular atrophy in the absence of SMN1. Nat Genet 30, 377-384.

Chen, C. Y., and Shyu, A. B. (1995). AU-rich elements: characterization and importance in mRNA degradation. Trends Biochem Sci 20, 465-470.

Cheng, H., Dufu, K., Lee, C. S., Hsu, J. L., Dias, A., and Reed, R. (2006). Human mRNA export machinery recruited to the 5' end of mRNA. Cell 127, 1389-1400.

Chew, S. L., Liu, H. X., Mayeda, A., and Krainer, A. R. (1999). Evidence for the function of an exonic splicing enhancer after the first catalytic step of pre-mRNA splicing. Proc Natl Acad Sci U S A 96, 10655-10660.

Chook, Y. M., and Blobel, G. (2001). Karyopherins and nuclear import. Curr Opin Struct Biol 11, 703-715.

Conaway, R. C., and Conaway, J. W. (2011). Function and regulation of the Mediator complex. Curr Opin Genet Dev 21, 225-230.

Connelly, S., and Manley, J. L. (1988). A functional mRNA polyadenylation signal is required for transcription termination by RNA polymerase II. Genes Dev 2, 440452.

Cramer, P., Bushnell, D. A., and Kornberg, R. D. (2001). Structural basis of transcription: RNA polymerase II at 2.8 angstrom resolution. Science 292, 1863-1876.

Cramer, P., Caceres, J. F., Cazalla, D., Kadener, S., Muro, A. F., Baralle, F. E., and Kornblihtt, A. R. (1999). Coupling of transcription with alternative splicing: RNA pol II 
promoters modulate SF2/ASF and 9G8 effects on an exonic splicing enhancer. Mol Cell 4, 251-258.

Culbertson, M. R., and Neeno-Eckwall, E. (2005). Transcript selection and the recruitment of mRNA decay factors for NMD in Saccharomyces cerevisiae. Rna 11, 1333-1339.

Custodio, N., Carmo-Fonseca, M., Geraghty, F., Pereira, H. S., Grosveld, F., and Antoniou, M. (1999). Inefficient processing impairs release of RNA from the site of transcription. Embo J 18, 2855-2866.

Danckwardt, S., Hentze, M. W., and Kulozik, A. E. (2008). 3' end mRNA processing: molecular mechanisms and implications for health and disease. Embo J 27, 482498.

Das, B., Butler, J. S., and Sherman, F. (2003). Degradation of normal mRNA in the nucleus of Saccharomyces cerevisiae. Mol Cell Biol 23, 5502-5515.

Das, R., Dufu, K., Romney, B., Feldt, M., Elenko, M., and Reed, R. (2006). Functional coupling of RNAP II transcription to spliceosome assembly. Genes Dev 20, 11001109.

Das, R., Yu, J., Zhang, Z., Gygi, M. P., Krainer, A. R., Gygi, S. P., and Reed, R. (2007). SR proteins function in coupling RNAP II transcription to pre-mRNA splicing. Mol Cell 26, 867-881.

de Almeida, S. F., and Carmo-Fonseca, M. (2008). The CTD role in cotranscriptional RNA processing and surveillance. FEBS Lett 582, 1971-1976.

Doma, M. K., and Parker, R. (2006). Endonucleolytic cleavage of eukaryotic mRNAs with stalls in translation elongation. Nature 440, 561-564.

Doma, M. K., and Parker, R. (2007). RNA quality control in eukaryotes. Cell 131, 660-668.

Dossani, Z. Y., Weirich, C. S., Erzberger, J. P., Berger, J. M., and Weis, K. (2009). Structure of the C-terminus of the mRNA export factor Dbp5 reveals the interaction surface for the ATPase activator Gle1. Proc Natl Acad Sci U S A 106, 16251-16256.

Dower, K., Kuperwasser, N., Merrikh, H., and Rosbash, M. (2004). A synthetic A tail rescues yeast nuclear accumulation of a ribozyme-terminated transcript. Rna 10, 1888-1899.

Dunn, E. F., Hammell, C. M., Hodge, C. A., and Cole, C. N. (2005). Yeast poly(A)-binding protein, Pab1, and PAN, a poly(A) nuclease complex recruited by Pab1, connect mRNA biogenesis to export. Genes Dev 19, 90-103.

Egloff, S., and Murphy, S. (2008). Role of the C-terminal domain of RNA polymerase II in expression of small nuclear RNA genes. Biochem Soc Trans 36, 537-539.

Estruch, F., and Cole, C. N. (2003). An early function during transcription for the yeast mRNA export factor Dbp5p/Rat8p suggested by its genetic and physical interactions with transcription factor IIH components. Mol Biol Cell 14, 16641676.

Fabrega, C., Shen, V., Shuman, S., and Lima, C. D. (2003). Structure of an mRNA capping enzyme bound to the phosphorylated carboxy-terminal domain of RNA polymerase II. Mol Cell 11, 1549-1561.

Fasken, M. B., and Corbett, A. H. (2009). Mechanisms of nuclear mRNA quality control. RNA Biol 6, 237-241. 
Fasken, M. B., Stewart, M., and Corbett, A. H. (2008). Functional significance of the interaction between the mRNA-binding protein, Nab2, and the nuclear poreassociated protein, Mlp1, in mRNA export. J Biol Chem 283, 27130-27143.

Fischer, T., Rodriguez-Navarro, S., Pereira, G., Racz, A., Schiebel, E., and Hurt, E. (2004). Yeast centrin Cdc31 is linked to the nuclear mRNA export machinery. Nat Cell Biol 6, 840-848.

Fischer, T., Strasser, K., Racz, A., Rodriguez-Navarro, S., Oppizzi, M., Ihrig, P., Lechner, J., and Hurt, E. (2002). The mRNA export machinery requires the novel Sac3p-Thp1p complex to dock at the nucleoplasmic entrance of the nuclear pores. Embo J 21, 5843-5852.

Fuda, N. J., Ardehali, M. B., and Lis, J. T. (2009). Defining mechanisms that regulate RNA polymerase II transcription in vivo. Nature 461, 186-192.

Galy, V., Gadal, O., Fromont-Racine, M., Romano, A., Jacquier, A., and Nehrbass, U. (2004). Nuclear retention of unspliced mRNAs in yeast is mediated by perinuclear Mlp1. Cell 116, 63-73.

Gilmour, D. S., and Lis, J. T. (1986). RNA polymerase II interacts with the promoter region of the noninduced hsp70 gene in Drosophila melanogaster cells. Mol Cell Biol 6, 39843989.

Glover-Cutter, K., Kim, S., Espinosa, J., and Bentley, D. L. (2008). RNA polymerase II pauses and associates with pre-mRNA processing factors at both ends of genes. Nat Struct Mol Biol 15, 71-78.

Gorlich, D., and Kutay, U. (1999). Transport between the cell nucleus and the cytoplasm. Annu Rev Cell Dev Biol 15, 607-660.

Grant, R. P., Marshall, N. J., Yang, J. C., Fasken, M. B., Kelly, S. M., Harreman, M. T., Neuhaus, D., Corbett, A. H., and Stewart, M. (2008). Structure of the N-terminal Mlp1-binding domain of the Saccharomyces cerevisiae mRNA-binding protein, Nab2. J Mol Biol 376, 1048-1059.

Green, D. M., Johnson, C. P., Hagan, H., and Corbett, A. H. (2003). The C-terminal domain of myosin-like protein 1 (Mlp1p) is a docking site for heterogeneous nuclear ribonucleoproteins that are required for mRNA export. Proc Natl Acad Sci U S A 100, 1010-1015.

Greenblatt, J., Nodwell, J. R., and Mason, S. W. (1993). Transcriptional antitermination. Nature 364, 401-406.

Gross, S., and Moore, C. (2001). Five subunits are required for reconstitution of the cleavage and polyadenylation activities of Saccharomyces cerevisiae cleavage factor I. Proc Natl Acad Sci U S A 98, 6080-6085.

Gruter, P., Tabernero, C., von Kobbe, C., Schmitt, C., Saavedra, C., Bachi, A., Wilm, M., Felber, B. K., and Izaurralde, E. (1998). TAP, the human homolog of Mex67p, mediates CTE-dependent RNA export from the nucleus. Mol Cell 1, 649-659.

Guzik, B. W., Levesque, L., Prasad, S., Bor, Y. C., Black, B. E., Paschal, B. M., Rekosh, D., and Hammarskjold, M. L. (2001). NXT1 (p15) is a crucial cellular cofactor in TAPdependent export of intron-containing RNA in mammalian cells. Mol Cell Biol 21, 2545-2554. 
Hilleren, P., McCarthy, T., Rosbash, M., Parker, R., and Jensen, T. H. (2001). Quality control of mRNA 3'-end processing is linked to the nuclear exosome. Nature 413, 538-542.

Hirose, Y., and Manley, J. L. (1998). RNA polymerase II is an essential mRNA polyadenylation factor. Nature 395, 93-96.

Hirose, Y., and Manley, J. L. (2000). RNA polymerase II and the integration of nuclear events. Genes Dev 14, 1415-1429.

Hodge, C. A., Colot, H. V., Stafford, P., and Cole, C. N. (1999). Rat8p/Dbp5p is a shuttling transport factor that interacts with Rat7p/Nup159p and Gle1p and suppresses the mRNA export defect of xpo1-1 cells. Embo J 18, 5778-5788.

Houseley, J., LaCava, J., and Tollervey, D. (2006). RNA-quality control by the exosome. Nat Rev Mol Cell Biol 7, 529-539.

Houseley, J., and Tollervey, D. (2008). The nuclear RNA surveillance machinery: the link between ncRNAs and genome structure in budding yeast? Biochim Biophys Acta $1779,239-246$.

Huang, Y., Gattoni, R., Stevenin, J., and Steitz, J. A. (2003). SR splicing factors serve as adapter proteins for TAP-dependent mRNA export. Mol Cell 11, 837-843.

Isken, O., and Maquat, L. E. (2007). Quality control of eukaryotic mRNA: safeguarding cells from abnormal mRNA function. Genes Dev 21, 1833-1856.

Isken, O., and Maquat, L. E. (2008). The multiple lives of NMD factors: balancing roles in gene and genome regulation. Nat Rev Genet 9, 699-712.

Izaurralde, E., Lewis, J., McGuigan, C., Jankowska, M., Darzynkiewicz, E., and Mattaj, I. W. (1994). A nuclear cap binding protein complex involved in pre-mRNA splicing. Cell 78, 657-668.

Kaida, D., Motoyoshi, H., Tashiro, E., Nojima, T., Hagiwara, M., Ishigami, K., Watanabe, H., Kitahara, T., Yoshida, T., Nakajima, H., et al. (2007). Spliceostatin A targets SF3b and inhibits both splicing and nuclear retention of pre-mRNA. Nat Chem Biol 3, 576-583.

Kazerouninia, A., Ngo, B., and Martinson, H. G. (2010). Poly(A) signal-dependent degradation of unprocessed nascent transcripts accompanies poly(A) signaldependent transcriptional pausing in vitro. Rna 16, 197-210.

Koch, F., Jourquin, F., Ferrier, P., and Andrau, J. C. (2008). Genome-wide RNA polymerase II: not genes only! Trends Biochem Sci 33, 265-273.

Kohler, A., and Hurt, E. (2007). Exporting RNA from the nucleus to the cytoplasm. Nat Rev Mol Cell Biol 8, 761-773.

Kohler, A., Pascual-Garcia, P., Llopis, A., Zapater, M., Posas, F., Hurt, E., and RodriguezNavarro, S. (2006). The mRNA export factor Sus1 is involved in Spt/Ada/Gen5 acetyltransferase-mediated $\mathrm{H} 2 \mathrm{~B}$ deubiquitinylation through its interaction with Ubp8 and Sgf11. Mol Biol Cell 17, 4228-4236.

Krumm, A., Meulia, T., Brunvand, M., and Groudine, M. (1992). The block to transcriptional elongation within the human c-myc gene is determined in the promoter-proximal region. Genes Dev 6, 2201-2213.

Kuehner, J. N., Pearson, E. L., and Moore, C. (2011). Unravelling the means to an end: RNA polymerase II transcription termination. Nat Rev Mol Cell Biol 12, 283-294. 
Le Hir, H., and Andersen, G. R. (2008). Structural insights into the exon junction complex. Curr Opin Struct Biol 18, 112-119.

Lebreton, A., and Seraphin, B. (2008). Exosome-mediated quality control: substrate recruitment and molecular activity. Biochim Biophys Acta 1779, 558-565.

Ledoux, S., and Guthrie, C. (2011). Regulation of the Dbp5 ATPase cycle in mRNP remodeling at the nuclear pore: a lively new paradigm for DEAD-box proteins. Genes Dev 25, 1109-1114.

Libri, D., Dower, K., Boulay, J., Thomsen, R., Rosbash, M., and Jensen, T. H. (2002). Interactions between mRNA export commitment, 3'-end quality control, and nuclear degradation. Mol Cell Biol 22, 8254-8266.

Licatalosi, D. D., Geiger, G., Minet, M., Schroeder, S., Cilli, K., McNeil, J. B., and Bentley, D. L. (2002). Functional interaction of yeast pre-mRNA 3' end processing factors with RNA polymerase II. Mol Cell 9, 1101-1111.

Liu, H. X., Zhang, M., and Krainer, A. R. (1998). Identification of functional exonic splicing enhancer motifs recognized by individual SR proteins. Genes Dev 12, 1998-2012.

Logan, J., Falck-Pedersen, E., Darnell, J. E., Jr., and Shenk, T. (1987). A poly(A) addition site and a downstream termination region are required for efficient cessation of transcription by RNA polymerase II in the mouse beta maj-globin gene. Proc Natl Acad Sci U S A 84, 8306-8310.

Lorentzen, E., Basquin, J., and Conti, E. (2008). Structural organization of the RNAdegrading exosome. Curr Opin Struct Biol 18, 709-713.

Lorentzen, E., and Conti, E. (2006). The exosome and the proteasome: nano-compartments for degradation. Cell 125, 651-654.

Lorincz, M. C., and Schubeler, D. (2007). RNA polymerase II: just stopping by. Cell 130, 1618.

Lund, M. K., and Guthrie, C. (2005). The DEAD-box protein Dbp5p is required to dissociate Mex67p from exported mRNPs at the nuclear rim. Mol Cell 20, 645-651.

Luo, M. J., and Reed, R. (1999). Splicing is required for rapid and efficient mRNA export in metazoans. Proc Natl Acad Sci U S A 96, 14937-14942.

Lykke-Andersen, S., Brodersen, D. E., and Jensen, T. H. (2009). Origins and activities of the eukaryotic exosome. J Cell Sci 122, 1487-1494.

Masuda, S., Das, R., Cheng, H., Hurt, E., Dorman, N., and Reed, R. (2005). Recruitment of the human TREX complex to mRNA during splicing. Genes Dev 19, 1512-1517.

Mattaj, I. W., and Englmeier, L. (1998). Nucleocytoplasmic transport: the soluble phase. Annu Rev Biochem 67, 265-306.

Max, T., Sogaard, M., and Svejstrup, J. Q. (2007). Hyperphosphorylation of the C-terminal repeat domain of RNA polymerase II facilitates dissociation of its complex with mediator. J Biol Chem 282, 14113-14120.

McCracken, S., Fong, N., Yankulov, K., Ballantyne, S., Pan, G., Greenblatt, J., Patterson, S. D., Wickens, M., and Bentley, D. L. (1997). The C-terminal domain of RNA polymerase II couples mRNA processing to transcription. Nature 385, 357-361.

McGlincy, N. J., and Smith, C. W. (2008). Alternative splicing resulting in nonsensemediated mRNA decay: what is the meaning of nonsense? Trends Biochem Sci 33, 385-393. 
McNeil, J. B., Agah, H., and Bentley, D. (1998). Activated transcription independent of the RNA polymerase II holoenzyme in budding yeast. Genes Dev 12, 2510-2521.

Milligan, L., Torchet, C., Allmang, C., Shipman, T., and Tollervey, D. (2005). A nuclear surveillance pathway for mRNAs with defective polyadenylation. Mol Cell Biol 25, 9996-10004.

Minvielle-Sebastia, L., Preker, P. J., Wiederkehr, T., Strahm, Y., and Keller, W. (1997). The major yeast poly(A)-binding protein is associated with cleavage factor IA and functions in premessenger RNA 3'-end formation. Proc Natl Acad Sci U S A 94, 7897-7902.

Montpetit, B., Thomsen, N. D., Helmke, K. J., Seeliger, M. A., Berger, J. M., and Weis, K. (2011). A conserved mechanism of DEAD-box ATPase activation by nucleoporins and InsP6 in mRNA export. Nature 472, 238-242.

Moraes, K. C. (2010). RNA surveillance: molecular approaches in transcript quality control and their implications in clinical diseases. Mol Med 16, 53-68.

Mosammaparast, N., and Pemberton, L. F. (2004). Karyopherins: from nuclear-transport mediators to nuclear-function regulators. Trends Cell Biol 14, 547-556.

Muhlemann, O., and Lykke-Andersen, J. (2010). How and where are nonsense mRNAs degraded in mammalian cells? RNA Biol 7, 28-32.

Muse, G. W., Gilchrist, D. A., Nechaev, S., Shah, R., Parker, J. S., Grissom, S. F., Zeitlinger, J., and Adelman, K. (2007). RNA polymerase is poised for activation across the genome. Nat Genet 39, 1507-1511.

Nag, A., Narsinh, K., and Martinson, H. G. (2007). The poly(A)-dependent transcriptional pause is mediated by CPSF acting on the body of the polymerase. Nat Struct Mol Biol 14, 662-669.

Nicholson, P., Yepiskoposyan, H., Metze, S., Zamudio Orozco, R., Kleinschmidt, N., and Muhlemann, O. (2010). Nonsense-mediated mRNA decay in human cells: mechanistic insights, functions beyond quality control and the double-life of NMD factors. Cell Mol Life Sci 67, 677-700.

Nojima, T., Hirose, T., Kimura, H., and Hagiwara, M. (2007). The interaction between capbinding complex and RNA export factor is required for intronless mRNA export. J Biol Chem 282, 15645-15651.

Orphanides, G., Lagrange, T., and Reinberg, D. (1996). The general transcription factors of RNA polymerase II. Genes Dev 10, 2657-2683.

Park, N. J., Tsao, D. C., and Martinson, H. G. (2004). The two steps of poly(A)-dependent termination, pausing and release, can be uncoupled by truncation of the RNA polymerase II carboxyl-terminal repeat domain. Mol Cell Biol 24, 4092-4103.

Pemberton, L. F., Blobel, G., and Rosenblum, J. S. (1998). Transport routes through the nuclear pore complex. Curr Opin Cell Biol 10, 392-399.

Peterlin, B. M., and Price, D. H. (2006). Controlling the elongation phase of transcription with P-TEFb. Mol Cell 23, 297-305.

Proudfoot, N. J., Furger, A., and Dye, M. J. (2002). Integrating mRNA processing with transcription. Cell 108, 501-512.

Reed, R. (2003). Coupling transcription, splicing and mRNA export. Curr Opin Cell Biol 15, 326-331. 
Reed, R., and Hurt, E. (2002). A conserved mRNA export machinery coupled to pre-mRNA splicing. Cell 108, 523-531.

Rocak, S., and Linder, P. (2004). DEAD-box proteins: the driving forces behind RNA metabolism. Nat Rev Mol Cell Biol 5, 232-241.

Rodriguez-Navarro, S., Fischer, T., Luo, M. J., Antunez, O., Brettschneider, S., Lechner, J., Perez-Ortin, J. E., Reed, R., and Hurt, E. (2004). Sus1, a functional component of the SAGA histone acetylase complex and the nuclear pore-associated mRNA export machinery. Cell 116, 75-86.

Roeder, R. G. (1996). The role of general initiation factors in transcription by RNA polymerase II. Trends Biochem Sci 21, 327-335.

Saunders, A., Core, L. J., and Lis, J. T. (2006). Breaking barriers to transcription elongation. Nat Rev Mol Cell Biol 7, 557-567.

Schmid, M., and Jensen, T. H. (2008). The exosome: a multipurpose RNA-decay machine. Trends Biochem Sci 33, 501-510.

Segref, A., Sharma, K., Doye, V., Hellwig, A., Huber, J., Luhrmann, R., and Hurt, E. (1997). Mex67p, a novel factor for nuclear mRNA export, binds to both poly(A)+ RNA and nuclear pores. Embo J 16, 3256-3271.

Shukla, A., Stanojevic, N., Duan, Z., Sen, P., and Bhaumik, S. R. (2006). Ubp8p, a histone deubiquitinase whose association with SAGA is mediated by Sgf11p, differentially regulates lysine 4 methylation of histone $\mathrm{H} 3$ in vivo. Mol Cell Biol 26, 3339-3352.

Shyu, A. B., Wilkinson, M. F., and van Hoof, A. (2008). Messenger RNA regulation: to translate or to degrade. Embo J 27, 471-481.

Sims, R. J., 3rd, Belotserkovskaya, R., and Reinberg, D. (2004). Elongation by RNA polymerase II: the short and long of it. Genes Dev 18, 2437-2468.

Singh, J., and Padgett, R. A. (2009). Rates of in situ transcription and splicing in large human genes. Nat Struct Mol Biol 16, 1128-1133.

Strasser, K., Masuda, S., Mason, P., Pfannstiel, J., Oppizzi, M., Rodriguez-Navarro, S., Rondon, A. G., Aguilera, A., Struhl, K., Reed, R., and Hurt, E. (2002). TREX is a conserved complex coupling transcription with messenger RNA export. Nature 417, 304-308.

Strobl, L. J., and Eick, D. (1992). Hold back of RNA polymerase II at the transcription start site mediates down-regulation of c-myc in vivo. Embo J 11, 3307-3314.

Strom, A. C., and Weis, K. (2001). Importin-beta-like nuclear transport receptors. Genome Biol 2, REVIEWS3008.

Sun, Q., Mayeda, A., Hampson, R. K., Krainer, A. R., and Rottman, F. M. (1993). General splicing factor SF2/ASF promotes alternative splicing by binding to an exonic splicing enhancer. Genes Dev 7, 2598-2608.

Tange, T. O., Nott, A., and Moore, M. J. (2004). The ever-increasing complexities of the exon junction complex. Curr Opin Cell Biol 16, 279-284.

Taniguchi, I., Masuyama, K., and Ohno, M. (2007). Role of purine-rich exonic splicing enhancers in nuclear retention of pre-mRNAs. Proc Natl Acad Sci U S A 104, 1368413689. 
Torchet, C., Bousquet-Antonelli, C., Milligan, L., Thompson, E., Kufel, J., and Tollervey, D. (2002). Processing of 3 '-extended read-through transcripts by the exosome can generate functional mRNAs. Mol Cell 9, 1285-1296.

Tran, E. J., Zhou, Y., Corbett, A. H., and Wente, S. R. (2007). The DEAD-box protein Dbp5 controls mRNA export by triggering specific RNA:protein remodeling events. Mol Cell 28, 850-859.

van Hoof, A., and Parker, R. (1999). The exosome: a proteasome for RNA? Cell 99, 347-350.

Vanacova, S., and Stefl, R. (2007). The exosome and RNA quality control in the nucleus. EMBO Rep 8, 651-657.

Vasudevan, S., Peltz, S. W., and Wilusz, C. J. (2002). Non-stop decay--a new mRNA surveillance pathway. Bioessays 24, 785-788.

Vinciguerra, P., Iglesias, N., Camblong, J., Zenklusen, D., and Stutz, F. (2005). Perinuclear Mlp proteins downregulate gene expression in response to a defect in mRNA export. Embo J 24, 813-823.

Visa, N., Izaurralde, E., Ferreira, J., Daneholt, B., and Mattaj, I. W. (1996). A nuclear capbinding complex binds Balbiani ring pre-mRNA cotranscriptionally and accompanies the ribonucleoprotein particle during nuclear export. J Cell Biol 133, 514.

Wang, J., Smith, P. J., Krainer, A. R., and Zhang, M. Q. (2005). Distribution of SR protein exonic splicing enhancer motifs in human protein-coding genes. Nucleic Acids Res 33, 5053-5062.

Weirich, C. S., Erzberger, J. P., Berger, J. M., and Weis, K. (2004). The N-terminal domain of Nup159 forms a beta-propeller that functions in mRNA export by tethering the helicase Dbp5 to the nuclear pore. Mol Cell 16, 749-760.

Weirich, C. S., Erzberger, J. P., Flick, J. S., Berger, J. M., Thorner, J., and Weis, K. (2006). Activation of the DExD/H-box protein Dbp5 by the nuclear-pore protein Gle1 and its coactivator InsP6 is required for mRNA export. Nat Cell Biol 8, 668-676.

Whitelaw, E., and Proudfoot, N. (1986). Alpha-thalassaemia caused by a poly(A) site mutation reveals that transcriptional termination is linked to $3^{\prime}$ end processing in the human alpha 2 globin gene. Embo J 5, 2915-2922.

Woychik, N. A., and Hampsey, M. (2002). The RNA polymerase II machinery: structure illuminates function. Cell 108, 453-463.

Wu, C. H., Yamaguchi, Y., Benjamin, L. R., Horvat-Gordon, M., Washinsky, J., Enerly, E., Larsson, J., Lambertsson, A., Handa, H., and Gilmour, D. (2003). NELF and DSIF cause promoter proximal pausing on the hsp70 promoter in Drosophila. Genes Dev 17, 1402-1414.

Wu, Y., Zhang, Y., and Zhang, J. (2005). Distribution of exonic splicing enhancer elements in human genes. Genomics 86, 329-336.

Yamaguchi, Y., Inukai, N., Narita, T., Wada, T., and Handa, H. (2002). Evidence that negative elongation factor represses transcription elongation through binding to a DRB sensitivity-inducing factor/RNA polymerase II complex and RNA. Mol Cell Biol 22, 2918-2927.

Yudkovsky, N., Ranish, J. A., and Hahn, S. (2000). A transcription reinitiation intermediate that is stabilized by activator. Nature 408, 225-229. 
Zaret, K. S., and Sherman, F. (1982). DNA sequence required for efficient transcription termination in yeast. Cell 28, 563-573.

Zeitlinger, J., Stark, A., Kellis, M., Hong, J. W., Nechaev, S., Adelman, K., Levine, M., and Young, R. A. (2007). RNA polymerase stalling at developmental control genes in the Drosophila melanogaster embryo. Nat Genet 39, 1512-1516.

Zenklusen, D., Vinciguerra, P., Wyss, J. C., and Stutz, F. (2002). Stable mRNP formation and export require cotranscriptional recruitment of the mRNA export factors Yra1p and Sub2p by Hpr1p. Mol Cell Biol 22, 8241-8253. 


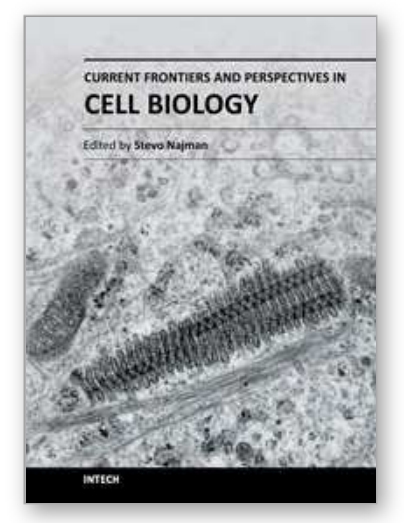

\section{Current Frontiers and Perspectives in Cell Biology \\ Edited by Prof. Stevo Najman}

ISBN 978-953-51-0544-2

Hard cover, 556 pages

Publisher InTech

Published online 25, April, 2012

Published in print edition April, 2012

\section{How to reference}

In order to correctly reference this scholarly work, feel free to copy and paste the following:

Naoko Fujiwara, Takuya Shiki and Seiji Masuda (2012). mRNA Biogenesis in the Nucleus and Its Export to the Cytoplasm, Current Frontiers and Perspectives in Cell Biology, Prof. Stevo Najman (Ed.), ISBN: 978-953-510544-2, InTech, Available from: http://www.intechopen.com/books/current-frontiers-and-perspectives-in-cellbiology/mrna-biogenesis-in-the-nucleus-and-its-export-to-the-cytoplasm

\section{INTECH}

open science | open minds

\section{InTech Europe}

University Campus STeP Ri

Slavka Krautzeka 83/A

51000 Rijeka, Croatia

Phone: +385 (51) 770447

Fax: +385 (51) 686166

www.intechopen.com

\section{InTech China}

Unit 405, Office Block, Hotel Equatorial Shanghai

No.65, Yan An Road (West), Shanghai, 200040, China

中国上海市延安西路65号上海国际贵都大饭店办公楼405单元

Phone: +86-21-62489820

Fax: +86-21-62489821 
(C) 2012 The Author(s). Licensee IntechOpen. This is an open access article distributed under the terms of the Creative Commons Attribution 3.0 License, which permits unrestricted use, distribution, and reproduction in any medium, provided the original work is properly cited. 